\title{
Characterization of Poly-hydroxybutyrate/Luffa Fibers Composite Material
}

\author{
Andrea Melina Avecilla-Ramírez, ${ }^{\mathrm{a}}$ Ma. del Rocío López-Cuellar, ${ }^{\mathrm{b}}$ Berenice Vergara- \\ Porras, ${ }^{c, d}$ Adriana I. Rodríguez-Hernández, ${ }^{b}$ and Edgar Vázquez-Núñez ${ }^{\text {a,* }}$
}

\begin{abstract}
Luffa fibers were evaluated as a reinforcement material in poly-hydroxybutyrate matrix composites. The treatments consisted of varying the incorporation percentage of mercerized and non-mercerized luffa fibers in a poly-hydroxybutyrate (PHB) matrix ( $5 \%, 10 \%$, and $20 \% \mathrm{w} / \mathrm{v})$. Composites made with PHB and reinforced with luffa fibers (treated and non-treated) were mechanically evaluated (tensile strength, Young's modulus, and percentage of elongation at break), the surface morphology was described by using scanning electronic microscopy, and the degradability behavior of composites was obtained. According to the results, mechanical properties decreased when the percentage of fibers increased and no significant effects were observed when compared with mercerized fiber composites. Degradability tests demonstrated that the weight loss increased with increased fiber content in composites, independent of the applied pretreatments. Microscopy images exhibited that mercerization improved the fiber incorporation into the polymeric matrix, diminishing the "pull out" effect; the above-mentioned result was supported by using the Fouriertransform infrared spectroscopy technique, observing the reduction of lignin and hemicellulose peaks in mercerized fibers. Based on the composite mechanical performance and degradability behavior, it was concluded that this material could be used in the packaging sector as biodegradable secondary packaging material.
\end{abstract}

Keywords: Alkali treatment; Biodegradation; PHB biocomposites; Natural fiber; Sustainable biomaterials

Contact information: a: Departamento de Ingenierías Química, Electrónica y Biomédica, División de Ciencias e Ingenierías, Campus León, Universidad de Guanajuato, León, Guanajuato, México, Lomas del Bosque 103, Lomas del Campestre, C.P. 37150; b: Cuerpo Académico de Biotecnología Agroalimentaria, Instituto de Ciencias Agropecuarias, Universidad Autónoma del Estado de Hidalgo, Avenida Universidad Km 1.0, Tulancingo 43600, Hidalgo, México; c: Escuela de Ingeniería y Ciencias, Tecnológico de Monterrey, Campus Estado de México, Carretera Lago de Guadalupe Km 3.5, Atizapán de Zaragoza 52926, Estado de México, México; d: Biology Department, Massachusetts Institute of Technology, Cambridge, MA 02142, USA; *Corresponding author: edgar.vazquez@ugto.mx

\section{INTRODUCTION}

In recent years, interest in the utilization of new renewable materials has rampantly increased, especially interest in those coming from non-valorized vegetable biomass (Popa 2018). These new green materials offer competitive advantages compared with oil-based polymers, such as their biodegradability and low cost (Muniyasamy et al. 2019), rendering them a sustainable alternative that can reduce negative environmental impacts (Varma 2019). The gradual substitution of petroleum-based materials with bio-based materials in diverse sectors, such as packaging, biomedicine, and construction, among others, has reduced the dependency on fossil fuel-based materials and decreased plastic solid wastes in landfills (Koronis et al. 2013; Luzi et al. 2019). Around the world, many research groups 
have centered their interest around developing new material using nature-based raw materials.

The introduction of natural fibers to reinforce bio-based polymers has attracted international interest because it was demonstrated that these blended materials show good physical, chemical, and mechanical properties, making them ideal for multiple applications (Peças et al. 2018). Among the most important advantages are the availability of their raw materials, their high tensile strength and relatively high modulus of elasticity, and the welldeveloped technology for manufacturing these blended composites (Duval and Lawoko 2014; Narayanan et al. 2015; Goh et al. 2018). Currently, the lignocellulosic residues have become relevant in the development of green materials due to their versatility and availability. Diverse studies have been published recently, reporting that these biopolymers have modifiable properties, and trying to determine why. One important factor in developing this mechanical performance lies in the chemical interactions between the cellulosic fibers and the polymeric matrix, which could be not only chemical in nature but also physical. In most of the reported cases, the interactions were the combination of both, due to the high hydrophobicity of lignin (Ali et al. 2018; Yang et al. 2019). There have been developed pretreatments, which are mainly chemical, such as mercerization (alkaline solution treatment of fibers), acetylation (treatment of fibers with acetic anhydride and sulfuric acid solutions), etc., in order to remove the lignin and facilitate its incorporation into the polymeric matrix and positively impact the properties mentioned above.

Luffa is a genus of subtropical and tropical vines in the cucumber family (Mohana Krishnudu et al. 2018; Ittah and Kwon-Ndung 2019). The term "luffa" refers specifically to the fruit of the two species Luffa aegyptiaca and Luffa acutangular. Luffa is distributed in tropical countries (Fig. 1) and, due to its high fiber content, it has been used as a sponge for cleaning and grooming services. It is produced in a non-industrialized manner, in many cases, by indigenous communities. Therefore, it is important to carry out studies that demonstrate its viability in the market, as it could represent an opportunity to improve the living standards of the producing communities.

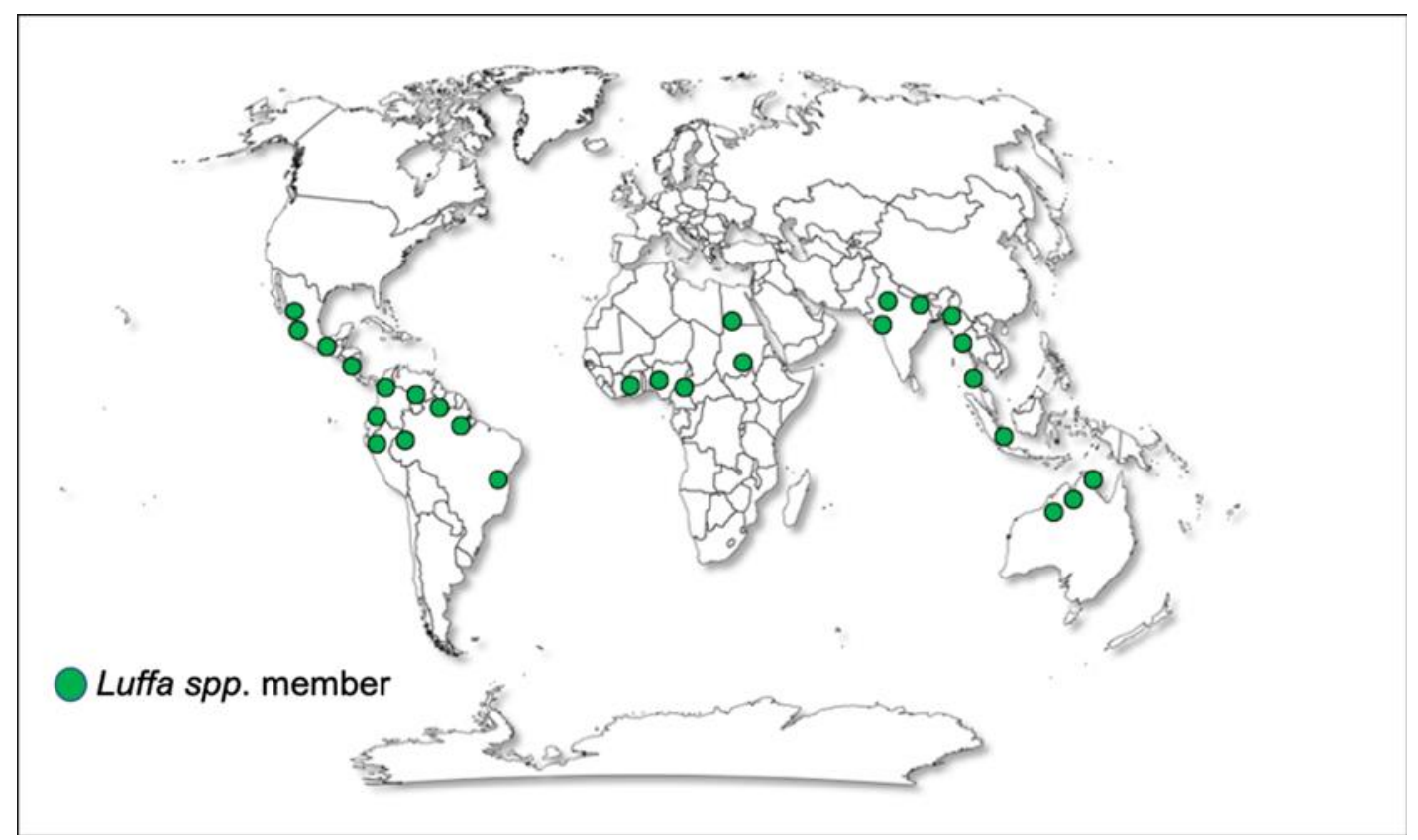

Fig. 1. Geographical distribution of Luffa spp. members 
Recently, diverse authors have executed novel research related to the uses of luffa, including, among other studies, Yang et al. (2018), who evaluated the photoactivity of $\mathrm{Fe}_{3} \mathrm{O}_{4} / \mathrm{Pr}-\mathrm{BiOC} / \mathrm{luffa}$ composites, and Tanobe et al. (2014), who described the process for incorporating sponge gourd into polyester composites and its effect on mechanical properties.

Guo et al. (2019) reported the characterization of treated and untreated luffa/poly(hydroxybutyrate-co-valerate) (PHBV) composites. The author observed that the chemical pretreatment (immersion in $\mathrm{NaOH}$ and $\mathrm{H}_{2} \mathrm{O}_{2}$ solutions) of the fibers resulted in a better moisture resistance of composites.

The luffa fiber has a high content of cellulose (60\%), hemicellulose (15\%), lignin (10\%), and other components (Mazali and Alves 2005). Its density is between 0.82 and $0.92 \mathrm{~g} \mathrm{~cm}^{-3}$ (Dairo et al. 2007), which is lower than other studied biomass, including sisal (1.26 $\mathrm{g} \mathrm{cm}^{-3}$ ) (Dun et al. 2019), hemp (1.48 $\mathrm{g} \mathrm{cm}^{-3}$ ) (Battegazzore et al. 2018), and cotton $\left(1.51 \mathrm{~g} \mathrm{~cm}^{-3}\right)$ (Abbott et al. 2010).

In the present study, the effects of carrying out a delignification pretreatment and the incorporation percentage of luffa fibers used as reinforcing material in a polyhydroxybutyrate matrix were investigated. The treated and untreated composites were examined to determine their mechanical performance and biodegradability behavior. Scanning electron microscopy (SEM) was undertaken to characterize the surface topology. To the best of our knowledge, this is the first attempt to develop a composite material based on PHB and luffa fibers, both treated and untreated. Finally, this new biobased composite could be a new class of sustainable material for the packaging industry.

\section{EXPERIMENTAL}

\section{Chemical Reagents and Luffa Fibers}

Polyhydroxybutyrate (PHB) $\left(M_{\mathrm{w}}=430 \mathrm{KDa}\right)$ was supplied by Goodfellow Cambridge Ltd. (\#BU396311, Huntingdon, England). According to the provider, the polymer had a density of $1.25 \mathrm{~g} \mathrm{~cm}^{-3}, 6 \%$ of elongation at break, a tensile modulus of 3.5 $\mathrm{GPa}$, and a tensile strength of $40 \mathrm{MPa}$. The luffa was obtained at local markets in León, Guanajuato, Mexico. The ripe and dried fruits were superficially cleaned with distilled water. The outer layer was removed, the sponge was cut, and the seeds removed. The sponge was size reduced using physical procedures and the pieces were stored in plastic bags at room temperature until their use.

\section{Pretreatment of Luffa Fibers}

The sliced pieces of luffa were washed thoroughly with distilled water; all impurities were removed and then dried in an oven at $70{ }^{\circ} \mathrm{C}$ for $24 \mathrm{~h}$.

Luffa fibers were mercerized (immersion in $5 \% \mathrm{w} / \mathrm{v} \mathrm{NaOH}$ solution) at constant stirring for $1 \mathrm{~h}$ at room temperature. Fibers were then washed repeatedly with distilled water to remove excess $\mathrm{NaOH}$ and oven-dried at $70{ }^{\circ} \mathrm{C}$ for $24 \mathrm{~h}$. Untreated fibers were immersed in distilled water following the same procedure. Both treated and untreated fibers were ground and sieved; the average size of fibers was between 0.4 and $0.7 \mathrm{~mm}$.

\section{Composite Fabrication}

The PHB/luffa fibers composites containing $0 \%, 5 \%, 10 \%$, and $20 \% \mathrm{w} / \mathrm{w}$ of treated and untreated fiber were prepared by the solvent casting method according to Pérez-Arauz 
et al. (2019). Neat PHB was mixed with chloroform (Sigma Aldrich, St. Louis, MO) at $10 \% \mathrm{w} / \mathrm{v}$ at $150{ }^{\circ} \mathrm{C}$ for $2 \mathrm{~h}$. Fibers were then added and mixed for $10 \mathrm{~min}$ at $60{ }^{\circ} \mathrm{C}$ and 150 rpm to allow the efficient dispersion of fibers in the matrix; the mix was executed in a 50 mL-glass bottle with a polypropylene cap (Pyrex®, Shanghai, China). The dissolved solution was poured into a glass container that had been previously heated to $60{ }^{\circ} \mathrm{C}$ and allowed to dry covered at room temperature for $24 \mathrm{~h}$.

\section{Fiber and Composite Characterization}

FTIR

The infrared spectrum of untreated and treated composites, as well as for all prepared composites, was recorded using Fourier transform infrared (FTIR) spectroscopy (Agilent Cary 630 FTIR, Santa Clara, CA, USA). Tests were performed at wavenumbers between $4000 \mathrm{~cm}^{-1}$ and $700 \mathrm{~cm}^{-1}$.

\section{Surface topology analysis}

The morphology of treated and untreated fibers, as well as composites, was analyzed by SEM in a JSM-6510LV microscope (JEOL, Tokyo, Japan). For better resolution, the samples were first covered with gold in a Desk II, Denton Vacuum (Denton Vacuum, Cherry Hill, NJ, USA).

\section{Mechanical characterization}

The mechanical characteristics in terms of tensile strength, percentage of elongation, and Young's modulus were evaluated in treated and untreated luffa fibers blended with PHB. The composites were conditioned in a chamber with controlled relative humidity $(50 \pm 10 \%)$, and an average temperature of $25^{\circ} \mathrm{C}$ over $48 \mathrm{~h}$ according to Kitic et al. (1986) and the corresponding ASTM standard (ASTM E104-02 2002). Composite samples $(10 \mathrm{~cm} \times 1 \mathrm{~cm} \times 0.6 \mathrm{~mm})$ were cut according to the specifications of the standard ASTM D882-02 (2002). The Young's modulus data were obtained from the force versus deformation curves using a universal testing machine (Instron, Model 4500, Canton, MA, USA). Tensile tests were performed at a deformation rate of $12.5 \mathrm{~mm} / \mathrm{min}$. For each test, nine specimens per treatment were tested and the average value was reported.

\section{Biodegradation}

Biodegradability behavior was determined by measuring weight loss in soil burial according to ASTM G160-03 (2003). Composite samples were cut into 3 x $2 \mathrm{~cm}$ pieces and buried at a depth of $10 \mathrm{~cm}$ in boxes containing agricultural soil. Soil moisture was monitored weekly and maintained at around 30\%. Samples were retrieved at 15, 30, 60, 90, and 120 days. Five specimens were measured at each time period for each sample.

In order to minimize the possibility of any contamination or matrix loss sample, retrieving and washing was done with utmost care.

\section{Statistical Analysis}

The statistical analysis was executed using the software IBM $^{\circledR}$ SPSS $^{\circledR}$ Statistic version 21 (IBM Corp., Redmond, WA, USA). The comparison between treatments was executed applying the Welch's ANOVA and Brown-Forsythe (BF) tests, since data did not satisfy variance homogeneity. Weight loss data per day was analyzed by one-way ANOVA. 


\section{RESULTS AND DISCUSSION}

\section{FTIR Spectroscopy}

The FTIR spectra of both treated and untreated L. cylindrica fibers are presented in Fig. 2. In the untreated fiber spectrum, typical cellulose peaks can be observed between 4000 and $600 \mathrm{~cm}^{-1}$. The $\mathrm{O}-\mathrm{H}$ stretching vibrations for cellulose, hemicellulose, and lignin can be assigned at $3335 \mathrm{~cm}^{-1}$ (Chen et al. 2017), while the peak at $2900 \mathrm{~cm}^{-1}$ corresponds to $\mathrm{C}-\mathrm{H}$ stretching vibrations in both cellulose and hemicellulose (Fiore et al. 2014; Chen et al. 2017). The absorbance peaks at 1415 and $1033 \mathrm{~cm}^{-1}$ are attributed to $\mathrm{O}-\mathrm{H}$ in-plane bending vibrations and $\mathrm{C}-\mathrm{O}$ stretching vibrations, respectively (NagarajaGanesh and Muralikannan 2016; Molina-Guerrero et al. 2018). The band at $895 \mathrm{~cm}^{-1}$ features the characteristic $\beta$-glycosidic linkage between anhydroglucose units (Oh et al. 2005; MolinaGuerrero et al. 2018).

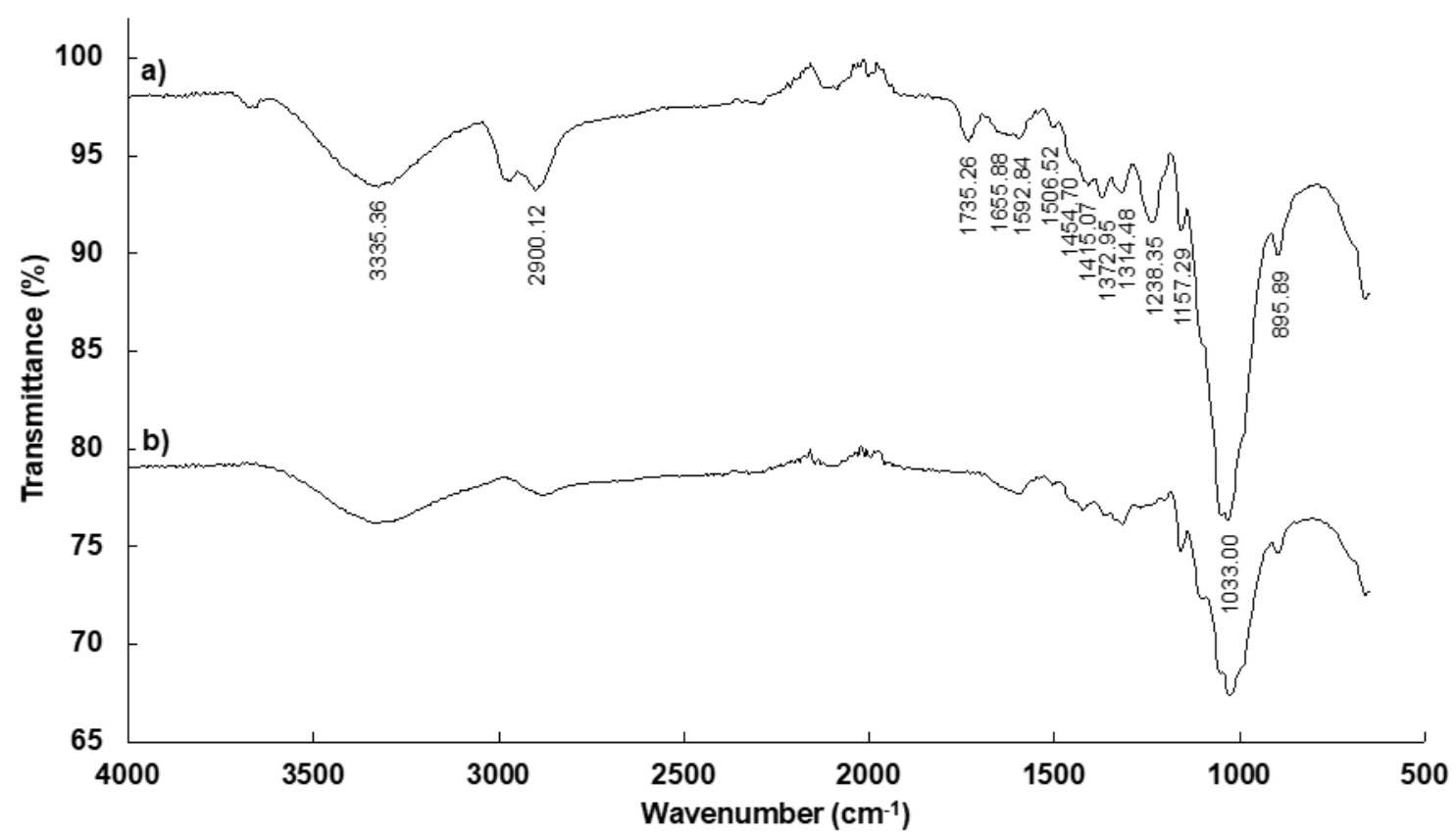

Fig. 2. Infrared spectrum for untreated (a) and treated (b) luffa fibers

Lignin in fibers can be correlated with different bands. Bands at $1655 \mathrm{~cm}^{-1}$ were due to stretching of the conjugated carbonyl group (Chen et al. 2018). Bands at $1592 \mathrm{~cm}^{-1}$ were indicative of the $\mathrm{C}=\mathrm{C}$ stretching of the aromatic ring (NagarajaGanesh and Muralikannan 2016). Those at $1454 \mathrm{~cm}^{-1}$ could be attributed to $\mathrm{C}-\mathrm{H}$ deformation stretching in either lignin or xylan molecules, the main component of hemicelluloses (Chen et al. 2018; Molina-Guerrero et al. 2018). At $1372 \mathrm{~cm}^{-1}$, bands indicated $\mathrm{C}-\mathrm{H}$ bending (Seki et al. 2013), and at $1157 \mathrm{~cm}^{-1}$ bands corresponded to $\mathrm{C}-\mathrm{O}-\mathrm{C}$ ring vibrational stretching (Kesraoui et al. 2016).

Absorbance peaks found at 1735 and $1238 \mathrm{~cm}^{-1}$ are associated with $\mathrm{C}=\mathrm{O}$ and $\mathrm{C}-\mathrm{O}$ stretching vibrations of the acetyl group in hemicellulose (Wang and Shen 2012; Chen et al. 2018). Both peaks were strongly reduced or almost absent after mercerization treatment. Infrared spectra of alkali-treated luffa in several studies have shown clear dampening of these bands (Wang and Shen 2012; Saw et al. 2013; Seki et al. 2013; Chen et al. 2017) because alkali treatment has been proven to accelerate the dissolution of acetyl groups in 
hemicelluloses (Chen et al. 2017). Furthermore, the xylan peak at $1454 \mathrm{~cm}^{-1}$ weakened. This value indicated that hemicelluloses in luffa fibers were partly removed due to alkali treatment.

Absorbance bands corresponding to lignin at 1655, 1454, and $1506 \mathrm{~cm}^{-1}$ also weakened to some extent, suggesting a partial removal of lignin in mercerized fibers. The spectra of PHB/luffa composites did not show differences between mercerized and raw fiber composites because the spectrum obtained was primarily that of PHB.
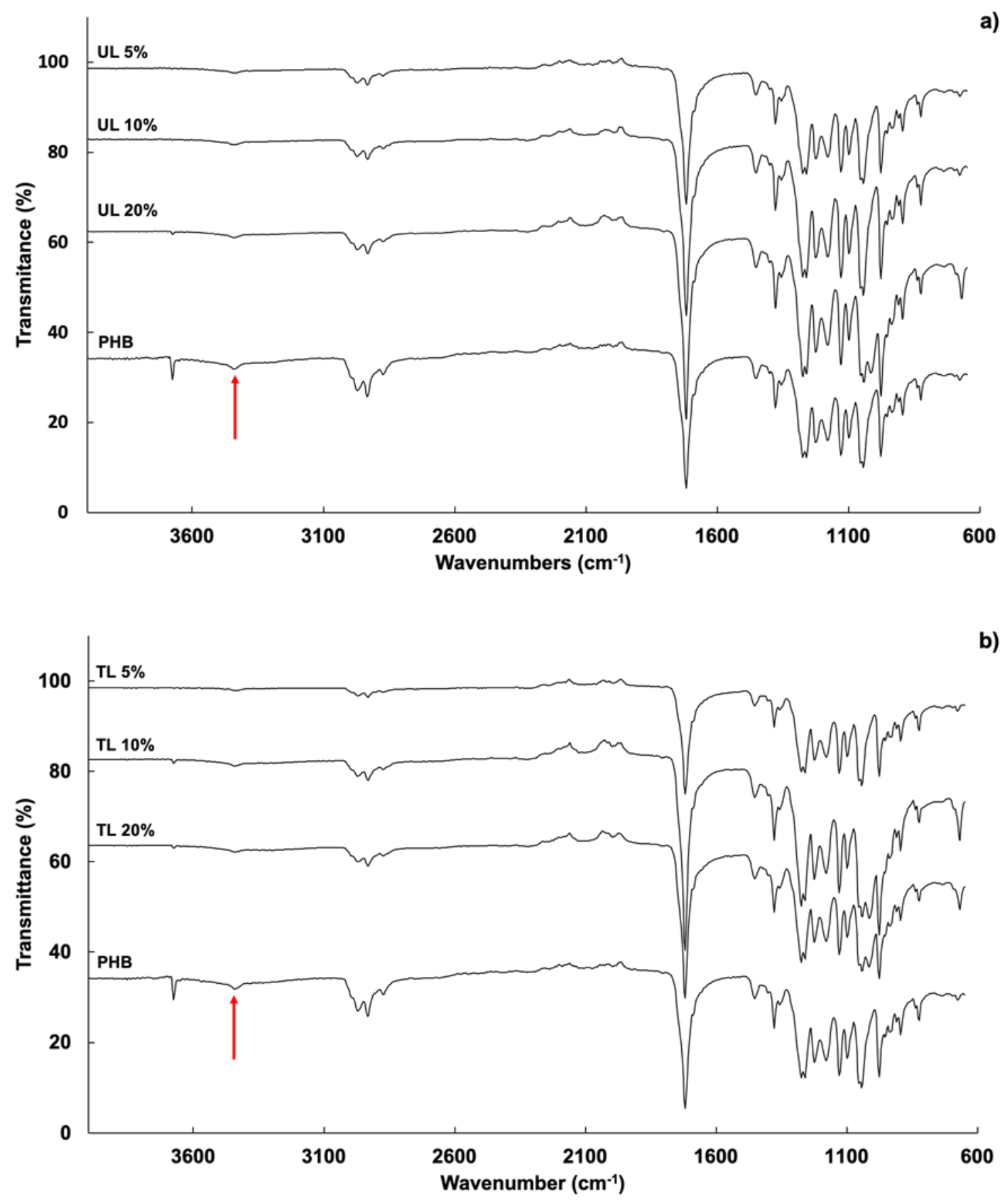

Fig. 3. The infrared spectrum for PHB composites reinforced with untreated (UL) (a) and treated (TL) (b) luffa fibers at different percentages of fiber content 
Changes in the intensity of characteristic PHB peaks were evident when comparing fiber content; intensity decreased with increasing fiber content as a result of reduced PHB concentration in the samples. It is relevant to mention that both sides of the films were analyzed, and the resulting spectra presented slight variances on each side, which could be expected as fibers were more exposed on one side of the films.

Hydrogen bonding between the matrix and the fiber is greatly desired because it can allow the transfer of stress to the fiber. The bonding can occur on hydroxyl groups present on the fiber surface, represented by peaks at approximately between 3600 and 3000 $\mathrm{cm}^{-1}$. Changes in these characteristic peaks reveal the formation of hydrogen bonds at the fiber-matrix interface. Increased pronunciation and widening of the bands indicates the formation of new hydrogen bonds from the free hydroxyl groups; if there is a good interaction between the fiber and the matrix, this effect would increase with the increase in the amount of fiber. Furthermore, the displacement of the band at a lower frequency indicates a higher level of hydrogen bonding; while a shift to a higher frequency points to little or no bonding (Mofokeng 2012; Gunning et al. 2013). The small peak found at approximately $3400 \mathrm{~cm}^{-1}$ for all composites (Fig. 3) suggested that hydrogen bonding was infrequent or nonexistent in the composites analyzed possibly due to a poor fiber-matrix interaction, which could affect mechanical properties.

\section{Surface Topology Analysis}

Figure 4 shows the SEM micrographs of raw and mercerized luffa fibers. It can be seen in Fig. 4a that impurities and small particles covering the surface of untreated fibersexpected to be mainly lignin, hemicelluloses, and waxy substances - had been removed due to alkaline treatment (see Fig. 4b).
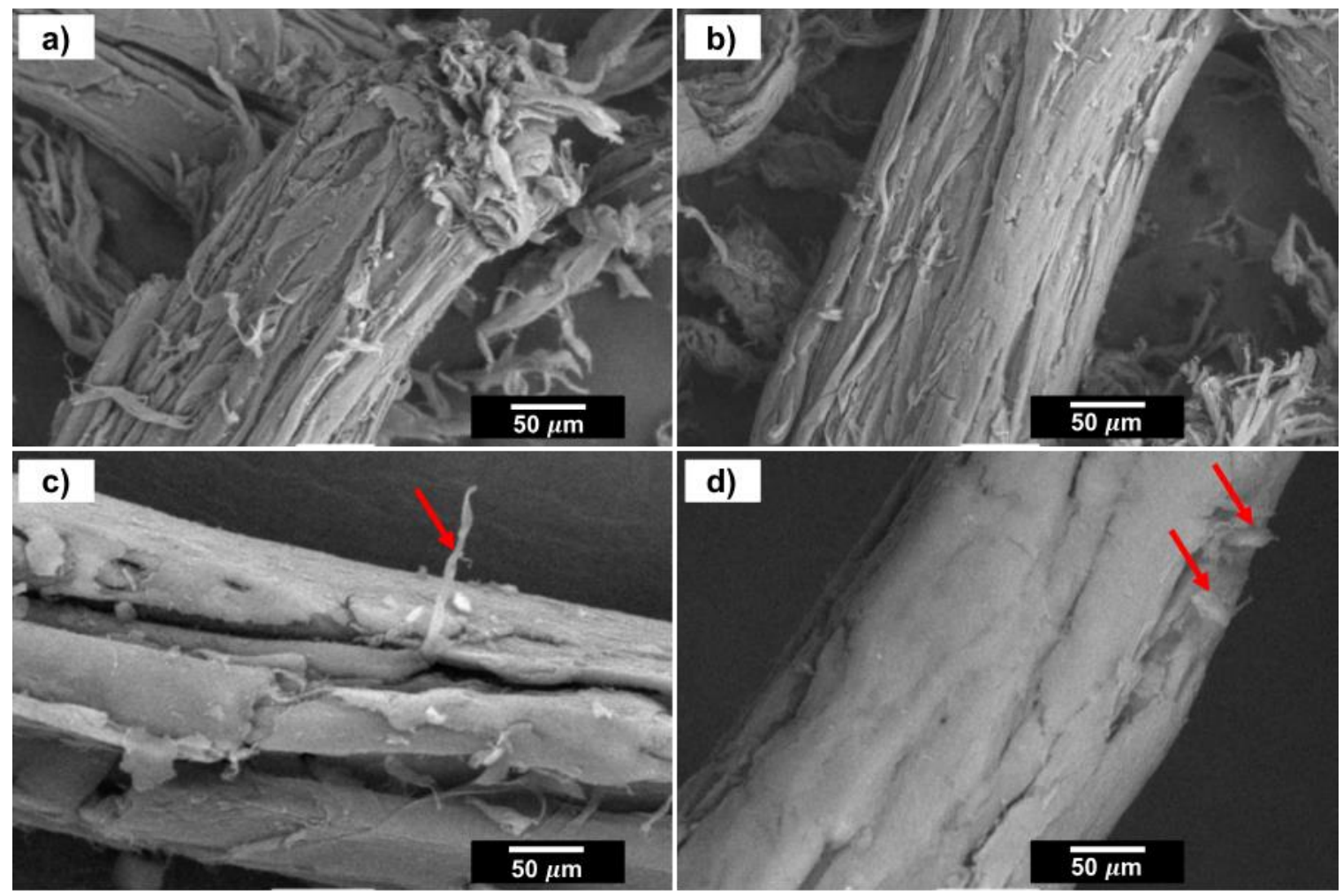

Fig. 4. Micrographs of untreated (a, c) and treated (b, d) luffa fibers 
A size estimation based on SEM images revealed a reduction in single fiber diameter of approximately $22 \%$ for treated fibers (images not shown). Additionally, Figs. $4 \mathrm{c}$ and $4 \mathrm{~d}$ show some microfibrils detached from the main body, which could have acted as mechanical anchors to the PHB matrix and therefore improve the fiber-matrix interfacial adhesion. However, contrary to the expected performance, the results of the mechanical tests did not show a positive effect. Similar effects of alkalization were previously reported by Russo et al. and Ibrahim et al. (Russo et al. 2013; Ibrahim et al. 2018).

The surface morphology of composite samples is shown in the SEM micrographs of Fig. 5. Poor fiber-matrix adhesion was observed in untreated fiber composites, along with the presence of voids and gaps, indicating low compatibility between the fiber and matrix (Beber et al. 2018). Mercerized fibers were better embedded in the matrix (Fig. 5b), and even showed residual resin on the luffa surface. This is shown in Fig. 5d, but it was not observed in the case of untreated fibers. This reflects an improved adhesion between the two materials; however, the composite surface still showed some voids, particularly closer to the fiber.
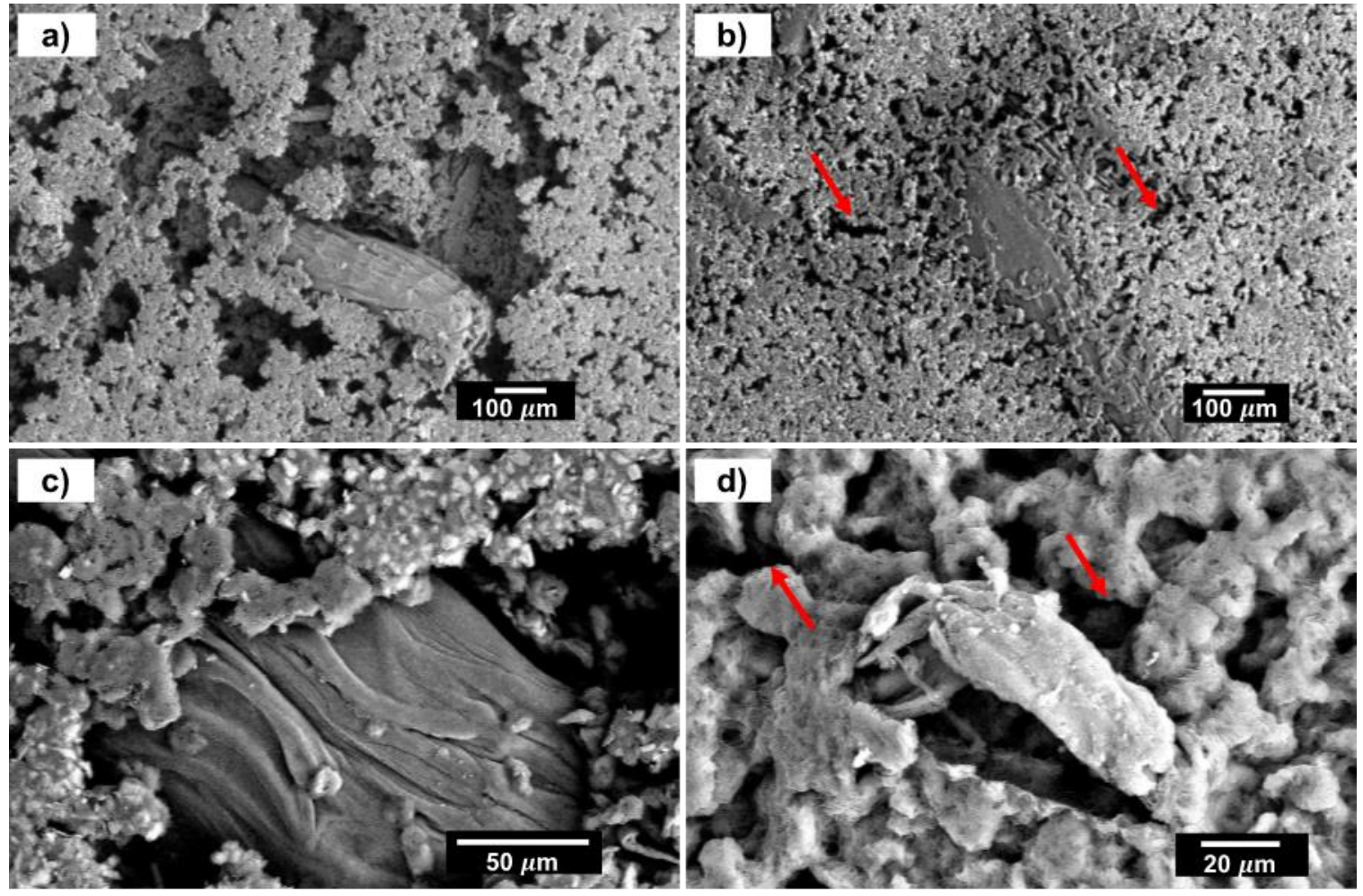

* Red arrows point to voids in the PHB matrix

Fig. 5. Surface micrographs of PHB composites with untreated $(a, c)$ and treated $(b, d)$ luffa fibers

Cryofractured samples were also observed by SEM. Figure 6 presents fractured surface micrographs of mercerized and non-mercerized composites with $10 \%$ fiber content. Untreated fiber composites exhibited several voids created by fiber pullouts (see Fig. 6a), as well as a clear interface gap between fiber and matrix (indicated in Fig. 6c). Literature shows that these characteristics are evidence of weak interfacial interaction between the fiber and the matrix, resulting in reduced performance of the composite material (Muthuraj et al. 2017). 
After alkali treatment, composites showed signs of improved adhesion, namely, fiber pullouts were markedly less, and the gap between fiber and matrix was visibly reduced, as portrayed in Figs. $6 \mathrm{~b}$ and $6 \mathrm{~d}$. However, the existence of both indicated that the interfacial adhesion was still not the strongest, which could limit the mechanical properties of the composite.
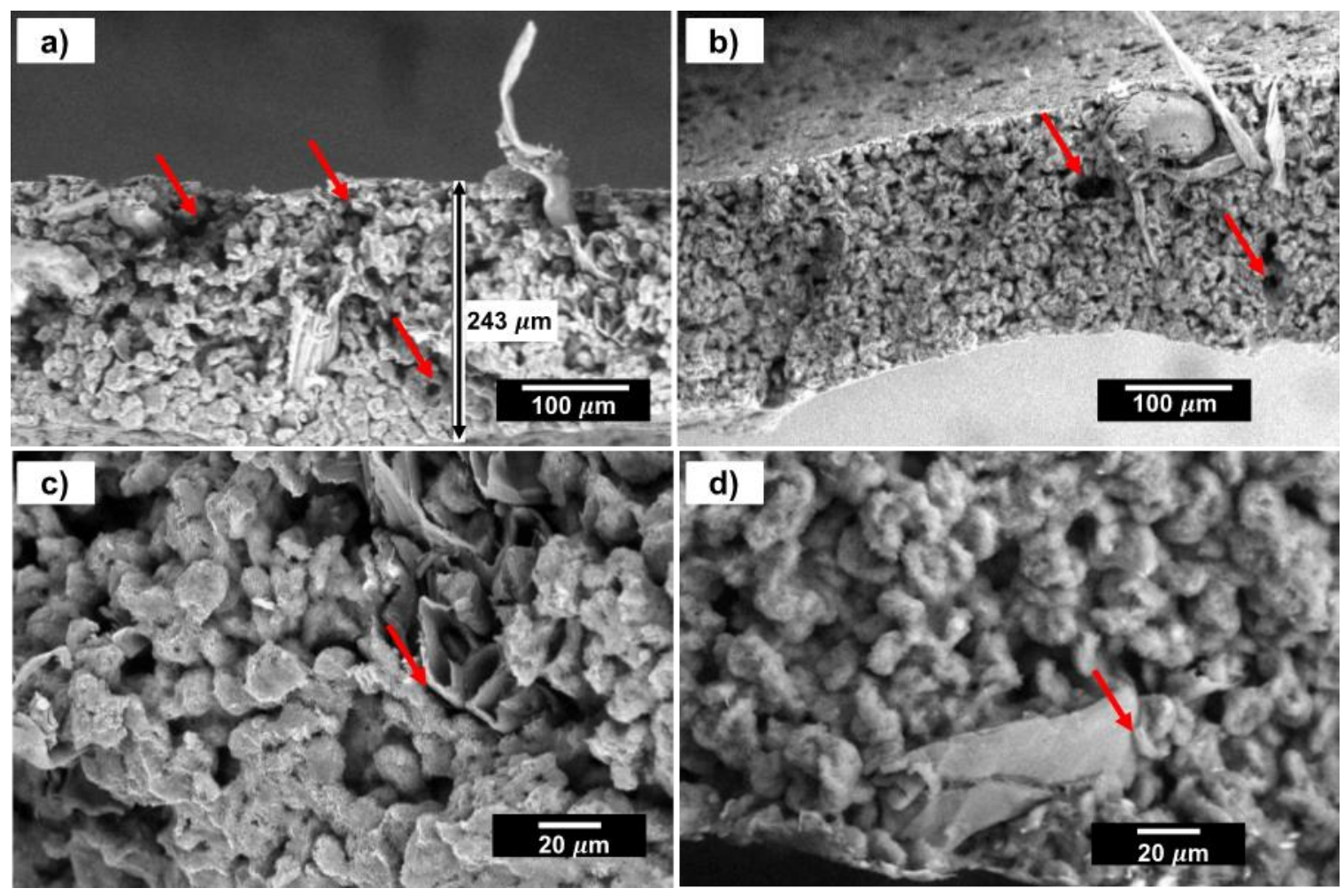

Fig. 6. Transversal micrographs of cryofractured PHB composites with untreated $(a, c)$ and treated (b, d) luffa fibers; in (a) and (b) red arrows point to fiber pullouts, while in (c) and (d), arrows point to interface gaps

\section{Mechanical Properties}

The mechanical behavior of PHB/luffa composites was analyzed by tensile tests. The obtained mechanical properties, including Young's modulus, tensile strength, and elongation at break, are summarized in Table 1.

Table 1. Mechanical Performance of PHB/Luffa Composites

\begin{tabular}{|c|c|c|c|}
\hline Composites (\% w/w) & $\begin{array}{c}\text { Young's Modulus } \\
(\mathrm{MPa})\end{array}$ & $\begin{array}{c}\text { Tensile Strength } \\
(\mathrm{MPa})\end{array}$ & $\begin{array}{c}\text { Elongation at } \\
\text { Break }(\%)\end{array}$ \\
\hline PHB & $412.3 \pm 44^{\mathrm{a}^{*}}$ & $4.3 \pm 0.6^{\mathrm{a}}$ & $2.3 \pm 0.5^{\mathrm{a}}$ \\
\hline UL5 & $343.5 \pm 29^{\mathrm{b}}$ & $3.6 \pm 0.5^{\mathrm{ab}}$ & $1.7 \pm 0.4^{\mathrm{ac}}$ \\
\hline UL10 & $288.1 \pm 23^{\mathrm{c}}$ & $3.1 \pm 0.5^{\mathrm{b}}$ & $1.5 \pm 0.3^{\mathrm{bc}}$ \\
\hline UL20 & $194.6 \pm 15^{\mathrm{d}}$ & $1.9 \pm 0.3^{\mathrm{c}}$ & $1.4 \pm 0.3^{\mathrm{bc}}$ \\
\hline TL5 & $272.9 \pm 40^{\mathrm{c}}$ & $3.1 \pm 0.3^{\mathrm{b}}$ & $1.8 \pm 0.3^{\mathrm{a}}$ \\
\hline TL10 & $260.0 \pm 20^{\mathrm{c}}$ & $2.8 \pm 0.3^{\mathrm{b}}$ & $1.6 \pm 0.2^{\mathrm{bc}}$ \\
\hline TL20 & $168.3 \pm 17^{\mathrm{d}}$ & $1.7 \pm 0.3^{\mathrm{c}}$ & $1.7 \pm 0.3^{\mathrm{bc}}$ \\
\hline
\end{tabular}

Same letter indicates no statistically significant differences. 
According to both Welch's ANOVA and BF tests, significant differences were found between composites for all mechanical properties tested ( $p>0.05)$. Tamhane T2 post hoc testing revealed statistical differences between specific composite formulations, which are reported in Table 1 by means of superscripts of the data.

A clear decrease was found in all tensile properties tested with fiber incorporation, regardless of fiber treatment. Furthermore, the mercerization of luffa fibers was found to have no significant effect on the mechanical behavior of composites. Increasing fiber content showed an inverse correlation to tensile strength and Young's modulus, excluding composites with $5 \%$ and $10 \%$ fiber, which revealed no statistical difference in tensile strength $(\mathrm{p}>0.05)$. In contrast, the elongation at break was not affected by fiber content ( $\mathrm{p}$ $>0.05)$.

Several studies have found similar responses in the tensile strength of PHAs with the addition of fiber. Batista et al. (2010) reported that the incorporation of $10 \% \mathrm{w} / \mathrm{w}$ of peach palm particles in a PHBV matrix produced a $35 \%$ decrease in tensile strength. However, when increasing fiber loading to $20 \%$ and $25 \% \mathrm{w} / \mathrm{w}$, there was no further reduction in tensile strength, indicating that the matrix-fiber adhesion was improved. A similar trend was observed for the strain at break. Young's modulus, in contrast, was unaffected by the incorporation of fiber, which was attributed to poor fiber impregnation and an inadequate fiber aspect ratio (length/diameter).

Melo et al. (2012) examined the effect of different fiber treatments on PHB/ carnauba fiber composites. Tensile strength of all composites decreased compared with neat PHB; nonetheless, and conversely to the results here obtained, fiber alkalization with $\mathrm{NaOH} 5 \%$ did exhibit a positive effect on tensile strength, improving $24 \%$ in comparison with untreated fiber composites, due to a better fiber-matrix interface adhesion caused by the amount of exposed cellulose generated by the treatment.

Reduction in tensile strength due to fiber addition was also described in PHB composites with jute and hemp fibers (Gunning et al. 2013); crude lignin-rich residues (Angelini et al. 2014); PBAT/babassu fibers (Beber et al. 2018); and almond shell, rice husk, and seagrass (Sánchez-Safont et al. 2018). As reported by Beber et al. (2018) and Sánchez-Safont et al. (2018) elongation at break dropped when incorporating fibers in all composites analyzed. Furthermore, Sánchez-Safont et al. (2018) found a more severe decrease in tensile strength and elongation at break with increasing fiber content, while Young's modulus presented a slight increase also dependent on fiber content.

The worsening of mechanical properties has been primarily attributed to poor compatibility between fiber and matrix, particularly for tensile strength and elongation at break, while Young's modulus is more influenced by fiber wettability and fiber aspect ratio (Batista et al. 2010; Nunes et al. 2018).

Optimum reinforcement is achieved when stress can be successfully transferred between matrix and fibers across the interface. Tensile strength therefore depends greatly on the interfacial adhesion. Low compatibility signifies limited interaction between the fiber and the matrix, leading to deficient interfacial bonding. Fiber impregnation or wettability can be considered an essential precursor to good fiber-matrix interfacial bonding. Poor fiber wettability generates interfacial defects, which can act as stress concentrators (Gunning et al. 2013; Pickering et al. 2016). Fiber treatments have been shown to improve wettability and, consequently, interfacial strength. For instance, Ventura et al. (2017) achieved a $25 \%$ improvement in tensile strength using flax fiber as reinforcement for PHB; however, when using plasma-treated fibers, tensile strength 
increased by $75 \%$. Plasma etching produced a rougher fiber surface, which could have contributed to better wettability and thus improved mechanical properties.

As shown in SEM micrographs (Fig. 4), fiber wettability, even after mercerization, appeared to be deficient, and hence the obtained results were not typical.

Fiber size and loading have been identified as major factors influencing the mechanical properties of composites, as both relate directly to fiber dispersion. To allow efficient reinforcement, the average fiber length must be greater than a critical length $\left(l_{c}\right)$. This parameter is determined by the length that allows the complete load transfer from matrix to fiber. At lengths below $l_{c}$, complete interfacial debonding is favored, while at lengths above $l_{\mathrm{c}}$, fiber failure occurs without interfacial debonding (Luz et al. 2018).

However, exceedingly long fibers can also reduce the reinforcement efficiency, as fibers might get tangled during mixing and thus hinder fiber dispersion. Composites analyzed by Gunning et al. (2013) exhibited the highest tensile properties with the greatest average fiber length, while composites with a fiber length lower than $l_{\mathrm{c}}$ did not surpass neat PHB tensile strength. It was also observed by the same author that the fiber width affects fiber dispersion, and it was proven that lower fiber widths attained better dispersion in the matrix. The best results were achieved with 10 to $20 \mu \mathrm{m}$ fiber width.

In general, when there is good fiber-matrix interfacial bonding, the strength and stiffness of composite materials have been seen to increase with fiber content. The opposite occurs if interfacial bonding is deficient, decreasing as fiber loading increases. Young's modulus, in contrast, generally increases with increasing fiber content regardless of the fiber-matrix affinity, though it increases more modestly when the interface is not ideal (Pickering et al. 2016; Moura et al. 2018).

A possible mechanism responsible for limited mechanical behavior is the formation of fiber agglomerates, whose presence becomes more prevalent with higher fiber loadings, causing weak points within the composite (Gunning et al. 2013). Porosity has also been known to largely influence these properties, as it increases with fiber loading. It can be caused by poor wettability, the inclusion of air during processing, and hollow features present in fibers (Pickering et al. 2016).

As fiber content increased in PHB/luffa composites, luffa fiber agglomerates became more evident and higher porosity was observed. These changes could explain the drop in tensile strength with higher fiber loading.

Good fiber dispersion is crucial to achieving good interfacial bonding, as it ensures that fibers will be completely covered by the matrix and that voids are reduced. Guo et al. (2019) achieved uniform fiber dispersion in PHBV/luffa fiber composites of up to $60 \%$ fiber content. Even the distribution of fibers favored the formation of an interlocked network structure that was able to withstand external loads, thus enhancing mechanical properties. However, with fiber content above $60 \%$, a large number of fibers were exposed, which reduced the interfacial bonding. In the present study, composites showed an uneven dispersion of fibers, particularly with higher fiber loadings, which most definitely influenced the mechanical properties in a negative way.

The manufacturing process has been reported to affect fiber dispersion. For instance, the use of a twin-screw extruder leads to better fiber dispersion than use of a single screw extruder (Pickering et al. 2016). Therefore, a process with more intensive mixing might enhance mechanical properties by improving fiber dispersion. 


\section{Biodegradation Behavior}

The biodegradation of PHB and PHB/luffa composites was evaluated by weight loss after soil burial for four months, according to ASTM G160-03 (2003), consistent with the procedure explained in the Experimental section.

The visual analysis of composites extracted at different times is displayed in Fig. 7.

\section{Days}

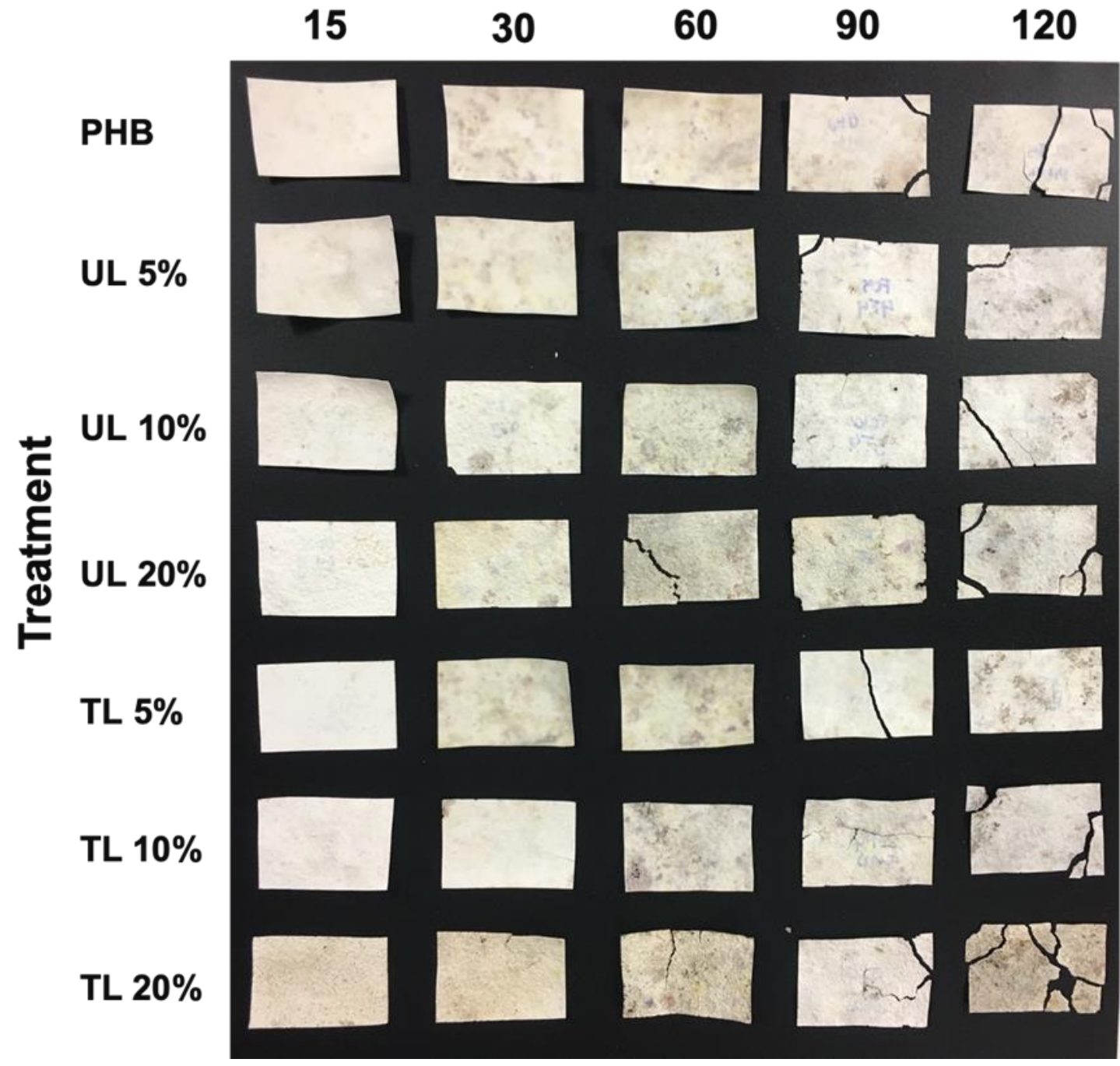

Fig. 7. Pictures of different stages of biodegradation of PHB/luffa fiber (untreated and treated) composites at different $\mathrm{w} / \mathrm{w}$ ratio after burial soil

In the composites and the neat $\mathrm{PHB}$, decomposition signs were evident after the first month. Samples became fragile, fragmenting easily, and surface roughness increased. According to Gunning et al. (2013), the first stage of biodegradation involves the surface attack on the polymer by microorganisms, increasing surface roughness and creating pores that, in turn, act as sites for a biological attack. Colored spots appeared on the surface, which intensified and multiplied with time, thus indicating microbial growth. 
Degradation of each composite was confirmed by a steady increase of weight loss as a function of time, which was statistically corroborated with one-way ANOVA testing and Tukey HSD post-hoc.

As shown in Fig. 8, the weight loss in composites for all samples started before the first measurement (15 days) and continued for the entire test duration, with no lag period noticed at the beginning of the process, as has been previously reported by Sánchez-Safont et al. (2018) and Seoane et al. (2018).

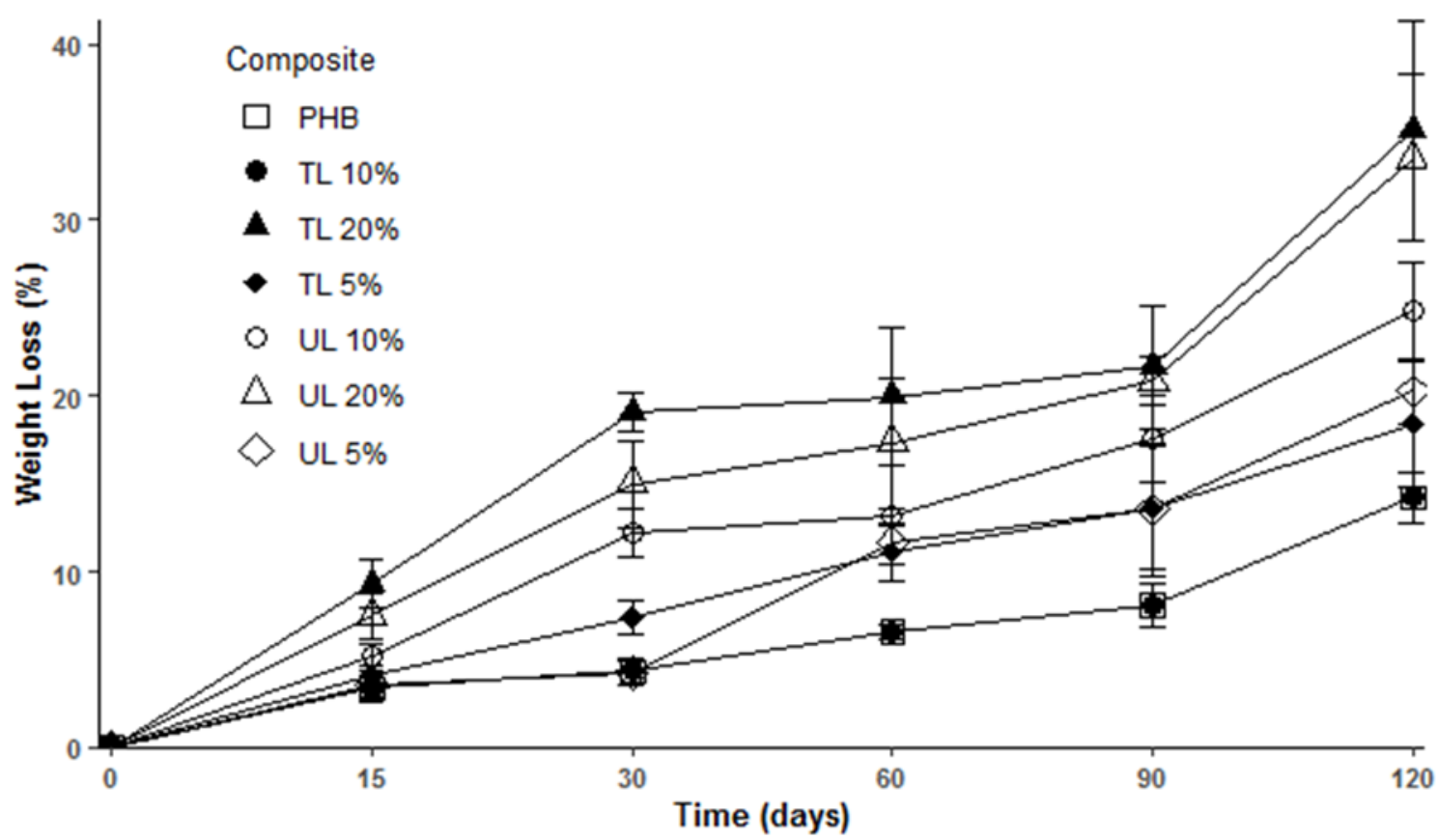

Fig. 8. Weight loss behavior of PHB/luffa fiber (untreated and treated) composites at different $\mathrm{w} / \mathrm{w}$ ratio after burial soil

Statistically significant differences were observed between composites on each measurement day, as shown by Welch's ANOVA and BF tests $(\mathrm{p}<0.05)$. Pairwise comparison by Tamhane T2 post hoc testing verified that all composites exhibited higher degradation rates than PHB alone. Weight loss due to biodegradation increased with increasing fiber loading in both treated and untreated fiber composites. Several studies (Batista et al. 2010; Wei et al. 2015; Joyyi et al. 2017; Cinelli et al. 2019) found similar results in PHA/fiber composites, and attributed this effect to the capacity of fibers to increase the water absorption and the accessibility of microorganisms to the composite's inner sites, therefore accelerating biodegradation (Ibrahim et al. 2017). Additionally, moisture uptake can increase the surface area for microbial attack, leading to the hydrolysis of ester groups on the $\mathrm{PHB}$ backbone, and then the conversion into $\mathrm{CO}_{2}$ and $\mathrm{H}_{2} \mathrm{O}$ by aerobic degradation (Wei et al. 2015). No statistical difference was found between treated and untreated fiber composites with the same fiber content percentage $(\mathrm{p}>0.05)$.

After 120 days, the PHB matrix reached nearly $15 \%$ weight loss, whereas composites with 5\%, 10\%, and 20\% fiber loading exhibited approximately 20\%, 25\%, and $35 \%$ decrease in weight, respectively. It is feasible to presume that biodegradation was the most likely reason for this weight loss, since microbial growth signs were observed in sample surfaces. 
It is worth mentioning that even though soil-burial test results may be affected by soil contamination on samples or loss of matrix during the recovery and cleaning process, the use of a standardized method and the precautions taken when handling samples ensure reliable results. However, as this method only considers the first stages of the biodegradation process, a respirometric analysis is recommended to obtain information on the degree of mineralization.

\section{CONCLUSIONS}

1. It was found that the alkali pretreatment of luffa fiber did not affect the mechanical properties of the composites. However, when increasing the luffa fiber content in the matrix, a decrease of the tensile strength and Young's modulus was observed. No differences were found for elongation at break parameters among the evaluated treatments.

2. The elimination of wax compounds was observed for treated fibers, confirming the effectiveness of the alkali treatment.

3. The weight loss analysis confirmed a positive correlation between fiber loading and degradation rate for all treatments; the lowest and highest fiber content percentages were statistically different between untreated and treated luffa.

\section{ACKNOWLEDGMENTS}

A. M. A.-R. thanks CONACYT for economic support (Scholarship 2018-00001201-NACF-03334); A. I. R.-H. and M. R. L.-C. thank CONACyT [269805]; E. V.-N. thanks B. V.-F. for her patient technical assistance, and the Universidad de Guanajuato for all the facilities. B. V.-P. thanks Tec de Monterrey, Campus Edo. de Mexico for all the support, and A. I. R.-H. and M. R. L.-C. thank the Cuerpo Académico de Biotecnología Agroalimentaria and UAEH for the facilities to develop this research.

\section{REFERENCES CITED}

Abbott, A. M., Higgerson, G. J., Long, R. L., Lucas, S. R., Naylor, G. R. S., Tischler, C. R., and Purmalis, M. M. (2010). "An instrument for determining the average fiber linear density (fineness) of cotton lint samples," Textile Research Journal 80(9), 822833. DOI: $10.1177 / 0040517509348335$

Ali, A., Shaker, K., Nawab, Y., Jabbar, M., Hussain, T., Militky, J., and Baheti, V. (2018). "Hydrophobic treatment of natural fibers and their composites-A review," Journal of Industrial Textiles 47(8), 2153-2183. DOI: 10.1177/1528083716654468

Angelini, S., Cerruti, P., Immirzi, B., Santagata, G., Scarinzi, G., and Malinconico, M. (2014). "From biowaste to bioresource: Effect of a lignocellulosic filler on the properties of poly(3-hydroxybutyrate)," International Journal of Biological Macromolecules 71, 163-173. DOI: 10.1016/j.ijbiomac.2014.07.038

ASTM D882-02 (2002). "Standard test method for tensile properties of thin plastic sheeting," ASTM International, West Conshohocken, PA, USA. 
ASTM E104-02 (2002). "Standard practice for maintaining constant relative humidity by means of aqueous solutions," ASTM International, West Conshohocken, PA, USA.

ASTM G160-03 (2003). "Standard practice for evaluating microbial susceptibility of nonmetallic materials by laboratory soil burial," ASTM International, West Conshohocken, PA, USA.

Batista, K. C., Silva, D. A. K., Coelho, L. A. F., Pezzin, S. H., and Pezzin, A. P. T. (2010). "Soil biodegradation of PHBV/peach palm particles biocomposites," Journal of Polymers and the Environment 18(3), 346-354. DOI: 10.1007/s10924-010-0238-4

Battegazzore, D., Alongi, J., Duraccio, D., and Frache, A. (2018). "All natural highdensity fiber and particleboards from hemp fibers or rice husk particles," Journal of Polymers and the Environment 26(4), 1652-1660. DOI: 10.1007/s10924-017-1071-9

Beber, V. C., De Barros, S., Banea, M. D., Brede, M., Carvalho, L. H., Hoffmann, R., Costa, A. R. M., Bezerra, E. B., Silva, I. D. S., Haag, K., et al. (2018). "Effect of babassu natural filler on PBAT/PHB biodegradable blends: An investigation of thermal, mechanical, and morphological behavior," Materials (Basel) 11(5), Article number 820. DOI: 10.3390/ma11050820

Chen, Y., Su, N., Zhang, K., Zhu, S., Zhao, L., Fang, F., Ren, L., and Guo, Y. (2017). "In-depth analysis of the structure and properties of two varieties of natural luffa sponge fibers," Materials (Basel) 10(5), Article number 479. DOI: 10.3390/ma10050479

Chen, Y., Su, N., Zhang, K., Zhu, S., Zhu, Z., Qin, W., Yang, Y., Shi, Y., Fan, S., Wang, Z., et al. (2018). "Effect of fiber surface treatment on structure, moisture absorption and mechanical properties of luffa sponge fiber bundles," Industrial Crops and Products 123, 341-352. DOI: 10.1016/j.indcrop.2018.06.079

Cinelli, P., Seggiani, M., Mallegni, N., Gigante, V., and Lazzeri, A. (2019). "Processability and degradability of PHA-based composites in terrestrial environments," International Journal of Molecular Sciences 20(2), Article number 284. DOI: 10.3390/ijms20020284

Dairo, F. A. S., Aye, P. A., and Oluwasola, T. A. (2007). "Some functional properties of loofah gourd (Luffa cylindrica L., M. J. Roem) seed," Journal of Food Agriculture and Environment 5(1), 91-101.

Dun, M., Hao, J., Wang, W., Wang, G., and Cheng, H. (2019). "Sisal fiber reinforced high density polyethylene pre-preg for potential application in filament winding," Composites Part B: Engineering 159, 369-377. DOI:

10.1016/j.compositesb.2018.09.090

Duval, A., and Lawoko, M. (2014). "A review on lignin-based polymeric, micro- and nano-structured materials," Reactive and Functional Polymers 85, 78-96. DOI: 10.1016/j.reactfunctpolym.2014.09.017

Fiore, V., Scalici, T., and Valenza, A. (2014). "Characterization of a new natural fiber from Arundo donax L. as potential reinforcement of polymer composites," Carbohydrate Polymers 106, 77-83. DOI: 10.1016/j.carbpol.2014.02.016

Goh, G. D., Dikshit, V., Nagalingam, A. P., Goh, G. L., Agarwala, S., Sing, S. L., Wei, J., and Yeong, W. Y. (2018). "Characterization of mechanical properties and fracture mode of additively manufactured carbon fiber and glass fiber reinforced thermoplastics," Materials \& Design 137, 78-89. DOI: 10.1016/j.matdes.2017.10.021

Gunning, M. A., Geever, L. M., Killion, J. A., Lyons, J. G., and Higginbotham, C. L. (2013). "Mechanical and biodegradation performance of short natural fibre 
polyhydroxybutyrate composites," Polymer Testing 32(8), 1603-1611. DOI:

10.1016/j.polymertesting.2013.10.011

Guo, Y., Wang, L., Chen, Y., Luo, P., and Chen, T. (2019). "Properties of luffa fiber reinforced PHBV biodegradable composites," Polymers 11(11), Article number 1765. DOI: $10.3390 /$ polym 11111765

Ibrahim, M. I., Hassan, M. Z., Dolah, R., Yusoff, M. Z. M., and Salit, M. S. (2018). "Tensile behaviour for mercerization of single kenaf fiber," Malaysian Journal of Fundamental and Applied Sciences 14(4), 437-439.

Ibrahim, N., Ab Wahab, M. K., Ngoc Uylan, D., and Ismail, H. (2017). "Physical and degradation properties of polylactic acid and thermoplastic starch blends - Effect of citric acid treatment on starch structures," BioResources 12(2), 3076-3087. DOI: 10.15376/biores.12.2.3076-3087

Ittah, M. A., and Kwon-Ndung, E. H. (2019). "Biometrical evaluation of morphological traits in family Cucurbitaceae in Lafia, Nigeria," Journal of Agriculture and Ecology Research International 19(2), 1-9. DOI: 10.9734/JAERI/2019/v19i230078

Joyyi, L., Ahmad Thirmizir, M. Z., Salim, M. S., Han, L., Murugan, P., Kasuya, K. I., Maurer, F. H. J., Zainal Arifin, M. I., and Sudesh, K. (2017). "Composite properties and biodegradation of biologically recovered $\mathrm{P}(3 \mathrm{HB}-c o-3 \mathrm{HHx})$ reinforced with short kenaf fibers," Polymer Degradation and Stability 137, 100-108. DOI: 10.1016/j.polymdegradstab.2017.01.004

Kesraoui, A., Moussa, A., Ali, G. B., and Seffen, M. (2016). "Biosorption of alpacide blue from aqueous solution by lignocellulosic biomass: Luffa cylindrica fibers," Environmental Science and Pollution Research 23(16), 15832-1584. DOI: 10.1007/s11356-015-5262-4

Kitic, D., Jardim, D. C. P., Favetto, G. J., Resnik, S. L., and Chirife, J. (1986). "Theoretical prediction of the water activity of standard saturated salt solutions at various temperatures," Journal of Food Science 51(4), 1037-1041. DOI: 10.1111/j.1365-2621.1986.tb11227.x

Koronis, G., Silva, A., and Fontul, M. (2013). "Green composites: A review of adequate materials for automotive applications," Composites Part B: Engineering 44(1), 120 127. DOI: 10.1016/j.compositesb.2012.07.004

Luz, F. S. D., Ramos, F. J. H. T. V., Nascimento, L. F. C., Figueiredo, A. B. H. D. S., and Monteiro, S. N. (2018). "Critical length and interfacial strength of PALF and coir fiber incorporated in epoxy resin matrix," Journal of Materials Research and Technology 7(4), 528-534. DOI: 10.1016/j.jmrt.2018.04.025

Luzi, F., Puglia, D., and Torre, L. (2019). "Natural fiber biodegradable composites and nanocomposites: A biomedical application," in: Biomass, Biopolymer-Based Materials, and Bioenergy, D. Verma, E. Fortunati, S. Jain, and X. Zhang (eds.), Woodhead Publishing, Sawston, UK, pp. 179-201. DOI: 10.1016/B978-0-08-1024263.00010-2

Mazali, I. O., and Alves, O. L. (2005). "Morphosynthesis: High fidelity inorganic replica of the fibrous network of loofa sponge (Luffa cylindrica)," Anais da Academia Brasileira de Ciências 77(1), 25-31. DOI: 10.1590/S0001-37652005000100003

Melo, J. D. D., Carvalho, L. F. M., Medeiros, A. M., Souto, C. R. O., and Paskocimas, C. A. (2012). "A biodegradable composite material based on polyhydroxybutyrate (PHB) and carnauba fibers," Composites Part B: Engineering 43(7), 2827-2835. DOI: 10.1016/j.compositesb.2012.04.046 
Mofokeng, J. P., Luyt, A. S., Tábi, T., and Kovács, J. (2012). "Comparison of injection moulded, natural fibre-reinforced composites with PP and PLA as matrices," Journal of Thermoplastic Composite Materials 25(8), 927-948. DOI:

10.1177/0892705711423291

Mohana Krishnudu, D., Sreeramulu, D., and Ramesh, N. (2018). "Synthesis, characterization, and properties of epoxy filled Luffa cylindrica reinforced composites," Materials Today: Proceedings 5(2), 3835-3841. DOI: 10.1016/j.matpr.2017.11.637

Molina-Guerrero, C. E., De La Rosa, G., Castillo-Michel, H., Sánchez, A., GarcíaCastañeda, C., Hernández-Rayas, A., Valdez-Vazquez, I., and Suarez-Vázquez, S. (2018). "Physicochemical characterization of wheat straw during a continuous pretreatment process," Chemical Engineering Technology 41(7), 1350. DOI: 10.1002/ceat.201800107

Moura, A., Bolba, C., Demori, R., Lima, L. P. F. C., and Santana, R. M. C. (2018). "Effect of rice husk treatment with hot water on mechanical performance in poly(hydroxybutyrate)/rice husk biocomposite," Journal of Polymers and the Environment 26(6), 2632-2639. DOI: 10.1007/s10924-017-1156-5

Muniyasamy, S., Mohanrasu, K., Gada, A., Teboho, M., Mtibe, A., Thulasinathan, B., Paul, V., and Arun, A. (2019). "Biobased biodegradable polymers for ecological applications: A move towards manufacturing sustainable biodegradable plastic products," in: Integrating Green Chemistry and Sustainable Engineering, S. Ul-Islam (ed.), Scrivener, Beverley, MA, USA, pp. 215-253. DOI:

10.1002/9781119509868.ch8

Muthuraj, R., Misra, M., and Mohanty, A. K. (2017). "Biodegradable biocomposites from poly(butylene adipate-co-terephthalate) and miscanthus: Preparation, compatibilization, and performance evaluation," Journal of Applied Polymer Science 134(43), 45448. DOI: 10.1002/app.45448

NagarajaGanesh, B., and Muralikannan, R. (2016). "Extraction and characterization of lignocellulosic fibers from Luffa cylindrica fruit," International Journal of Polymer Analysis and Characterization 21(3), 259-266. DOI: 10.1080/1023666X.2016.1146849

Narayanan, K. B., Suresh, A. K., and Sakthivel, N. (2015). "Metallic nanocomposites: Bacterial-based ecologically benign biofabrication and optimization studies," in: Ecofriendly Polymer Nanocomposites: Processing and Properties, V. K. Thajur, and M. K. Thakur (eds.), Springer, New Delhi, India, pp. 215-231. DOI: 10.1007/978-81322-2470-9_7

Nunes, M. A. B. S., Marinho, V. A. D., Falcão, G. A. M., Canedo, E. L., Bardi, M. A. G., and Carvalho, L. H. (2018). "Rheological, mechanical and morphological properties of poly(butylene adipate-co-terephthalate)/thermoplastic starch blends and its biocomposite with babassu mesocarp," Polymer Testing 70, 281-288. DOI: 10.1016/j.polymertesting.2018.07.009

Oh, S. Y., Yoo, D. I., Shin, Y., Kim, H. C., Kim, H. Y., Chung, Y. S., Park, W. H., and Youk, J. H. (2005). "Crystalline structure analysis of cellulose treated with sodium hydroxide and carbon dioxide by means of X-ray diffraction and FTIR spectroscopy," Carbohydrate Research 340(15), 2376-2391. DOI: 10.1016/j.carres.2005.08.007

Peças, P., Carvalho, H., Salman, H., and Leite, M. (2018). "Natural fibre composites and their applications: A review," Journal of Composites Science 2(4), Article number 66. DOI: $10.3390 /$ jcs2040066 
Pérez-Arauz, A. O., Aguilar-Rabiela, A. E., Vargas-Torres, A., Rodríguez-Hernández, A. I., Chavarría-Hernández, N., Vergara-Porras, B., and López-Cuellar, M. R. (2019). "Production and characterization of biodegradable films of a novel polyhydroxyalkanoate (PHA) synthesized from peanut oil," Food Packaging and Shelf Life 20, Article ID 100297. DOI: 10.1016/j.fpsl.2019.01.001

Pickering, K. L., Efendy, M. G. A., and Le, T. M. (2016). "A review of recent developments in natural fibre composites and their mechanical performance," Composites Part A: Applied Science and Manufacturing 83, 98-112. DOI: 10.1016/j.compositesa.2015.08.038

Popa, V. I. (2018). "Biomass for fuels and biomaterials," in: Biomass as Renewable Raw Material to Obtain Bioproducts of High-Tech Value, V. Popa, and I. Volf (eds.), Elsevier, London, UK, pp. 1-37. DOI: 10.1016/B978-0-444-63774-1.00001-6

Russo, P., Carfagna, C., Cimino, F., Acierno, D., and Persico, P. (2013). "Biodegradable composites reinforced with kenaf fibers: Thermal, mechanical, and morphological issues," Advances in Polymer Technology 32(S1), E313-E322. DOI: 10.1002/adv.21282

Sánchez-Safont, E. L., Aldureid, A., Lagarón, J. M., Gámez-Pérez, J., and Cabedo, L. (2018). "Biocomposites of different lignocellulosic wastes for sustainable food packaging applications," Composites Part B: Engineering 145, 215-225. DOI: 10.1016/j.compositesb.2018.03.037

Saw, S. K., Purwar, R., Nandy, S., Ghose, J., and Sarkhel, G. (2013). "Fabrication, characterization, and evaluation of Luffa cylindrica fiber reinforced epoxy composites," BioResources 8(4), 4805-4826. DOI: 10.15376/biores.8.4.4805-4826

Seki, Y., Sarikanat, M., Sever, K., and Durmuşkahya, C. (2013). "Extraction and properties of Ferula communis (chakshir) fibers as novel reinforcement for composites materials," Composites Part B: Engineering 44(1), 517-523. DOI: 10.1016/j.compositesb.2012.03.013

Seoane, I. T., Manfredi, L. B., and Cyras, V. P. (2018). "Bilayer biocomposites based on coated cellulose paperboard with films of polyhydroxybutyrate/cellulose nanocrystals," Cellulose 25(4), 2419-2434. DOI: 10.1007/s10570-018-1729-z

Tanobe, V. O. A., Flores-Sahagun, T. H. S., Amico, S. C., Muniz, G. I. B., and Satyanarayana, K. G. (2014). "Sponge gourd (Luffa cylindrica) reinforced polyester composites: Preparation and properties," Defense Science Journal 64(3), 273-280. DOI: $10.14429 / \mathrm{dsj} .64 .7327$

Varma, R. S. (2019). "Biomass-derived renewable carbonaceous materials for sustainable chemical and environmental applications," ACS Sustainable Chemistry and Engineering 7(7), 6458-6470. DOI: 10.1021/acssuschemeng.8b06550

Ventura, H., Claramunt, J., Rodríguez-Pérez, M. A., and Ardanuy, M. (2017). "Effects of hydrothermal aging on the water uptake and tensile properties of PHB/flax fabric biocomposites," Polymer Degradation and Stability 142, 129-138. DOI: 10.1016/j.polymdegradstab.2017.06.003

Wang, Y., and Shen, X.-Y. (2012). "Optimum plasma surface treatment of luffa fibers," Journal of Macromolecular Science, Part B 51(4), 662-670. DOI: 10.1080/00222348.2011.598104

Wei, L., Liang, S., and McDonald, A. G. (2015). "Thermophysical properties and biodegradation behavior of green composites made from polyhydroxybutyrate and potato peel waste fermentation residue," Industrial Crops and Products 69, 91-103. DOI: 10.1016/j.indcrop.2015.02.011 
Yang, J., Chee, C. Y., and Chuah, C. H. (2019). "Applications of lignocellulosic fibers and lignin in bioplastics: A review," Polymers 11(5), Article number 751. DOI: 10.3390/polym 11050751

Yang, Q., Zhai, Y., Li, X., and Li, H. (2018). "Synthesis of $\mathrm{Fe}_{3} \mathrm{O}_{4} / \mathrm{Pr}-\mathrm{BiOCl} / \mathrm{luffa}$ composites with enhanced visible light photoactivity for organic dyes degradation," Materials Research Bulletin 106, 409-417. DOI: 10.1016/j.materresbull.2018.06.029

Article submitted: May 9, 2020; Peer review completed: July 12, 2020; Revised version received and accepted: July 28, 2020; Published: July 31, 2020.

DOI: 10.15376/biores.15.3.7159-7177 